\title{
Erratum
}

\section{Successful treatment of hyperphagia by resection of a hypothalamic hamartoma}

\section{Case report}

To The EDITOR: Thank you for publishing our paper entitled "Successful treatment of hyperphagia by resection of a hypothalamic hamartoma. Case report" ( $\mathrm{J} \mathrm{Neu}$ rosurg Pediatrics, published online ahead of print, on April 9, 2013; DOI: 10.3171/2013.2.PEDS12552). After our paper had been published online, we realized that one of our affiliations was misnamed and another omitted. The University of Texas Health Science Center at Houston Medical School was mistakenly listed as the University of Texas-Houston; also, Miami Children's Hospital and the University of Miami Miller School of Medicine were omitted.

The corrected list of authors and affiliations for this paper is shown below:

\footnotetext{
Yoshua Esquenazi, M.D., ${ }^{1}$ David I. SANDberG, M.D., ${ }^{1,2}$ AND HaROLD L. REKATE, M.D. ${ }^{3}$

${ }^{1}$ Departments of Neurosurgery and Pediatric Surgery, The University of Texas Health Science Center at Houston Medical School, Children's Memorial Hermann Hospital, and Mischer Neuroscience Institute, Houston, Texas; ${ }^{2}$ Division of Neurosurgery, Miami Children's Hospital, and Department of Neurosurgery, University of Miami Miller School of Medicine, Miami, Florida; and ${ }^{3}$ The Chiari Institute, Hofstra Northshore-LIJ College of Medicine, Great Neck, New York
}

We apologize for any inconvenience the error has caused the readers. We are pleased to have the opportunity to make this correction. The error was corrected online as of April 26, 2013, and appears correctly in print in this issue.

DAVID I. SANDBERG, M.D.

The University of Texas Health Science Center at Houston Medical School Houston, Texas

Please include this information when citing this paper: published online April 26, 2013; DOI: 10.3171/2013.4.PEDS12552a. 